Check for updates

Cite this: RSC Adv., 2018, 8, 28637

Received 7th May 2018

Accepted 6th August 2018

DOI: $10.1039 / c 8 r a 03882 a$

rsc.li/rsc-advances

\title{
Transition-metal-free base catalyzed intramolecular cyclization of 2-ynylphenols for efficient and facile synthesis of 2-substituted benzo [b]furans $\dagger$
}

\author{
Yong Liu, (D) Tao Lu, Wei-Fang Tang* and Jian Gao (D) *
}

A transition-metal-free base catalyzed intramolecular cyclization of 2-ynylphenols was developed for the facile synthesis of 2-substituted benzo[b]furans. Various 2-aryl and 2-alkyl substituted benzo[b]furans can be obtained with good to excellent yields using readily available $\mathrm{Cs}_{2} \mathrm{CO}_{3}$ as the catalyst under mild reaction conditions. The broad substrates scope and the typical maintenance of vigorous efficiency on gram scale make this protocol a potentially practical method to synthesize 2-substituted benzo[b]furans derivatives.

\section{Introduction}

2-Substituted benzo[ $[b]$ furans are a significant structural scaffold especially in the pharmaceutical industry, both for natural and synthesized products, and have exhibited a broad range of biological and pharmacological activities. ${ }^{1-3}$ Typical pharmaceutical application of 2-substituted benzo[b]furan moiety bearing compounds (Fig. 1) that have been developed include those of drugs or agents used for anti-hyperlipemia, ${ }^{4}$ antimicrobial, ${ }^{5}$ anti-inflammatory, ${ }^{6}$ antifungal $^{2}$ and so on. Therefore, considerable efforts have been directed toward the development of efficient methods for the synthesis of 2-substituted benzo[ $b]$ furan derivatives. Among the various synthetic approaches, transition metal catalyzed intramolecular cyclization of 2-ynylphenols (Scheme 1a) represents one type of important strategy leading to 2 -substituted benzo $[b]$ furan skeletons. Various precious metals such as $\mathrm{Pt},{ }^{7} \mathrm{Pd},{ }^{8} \mathrm{Au} / \mathrm{Ag},{ }^{9} \mathrm{Au},{ }^{10} \mathrm{Rh}^{11}$ and $\operatorname{Ir}^{12}$ as well as other non-precious metals such as $\mathrm{Zn}^{13}$ and $\mathrm{Cu}^{14}$ have been developed as catalysts in the presence of stoichiometric base in most cases.

On the other hand, another representative pathway to 2substituted benzo $[b]$ furans was transition metal promoted ${ }^{\mathbf{1 5}}$ or catalyzed $^{16-18}$ one-pot synthesis from 2-halophenols and terminal alkynes through Sonogashira coupling followed by intramolecular cyclization of the corresponding 2-ynylphenol intermediates generated in situ (Scheme 1b). In this context, ligands and high reaction temperatures were usually

Department of Organic Chemistry, China Pharmaceutical University, 24 Tong Jia Xiang, Nanjing, 210009, P. R. China. E-mail: tangwf126@126.com; gaojian@cpu. edu.cn

$\dagger$ Electronic supplementary information (ESI) available: General experimental methods and procedures, characterization and spectra of substrates and products and other supplementary information. See DOI: 10.1039/c8ra03882a unavoidable to satisfy the incipient Sonogashira coupling reaction which might bring some restrictions to their application. Competitively, one-pot synthesis of 2-substituted benzo[ $b]$ furans directly from phenols ${ }^{19}$ was also developed yet still could not get rid of transition metals catalysts. Taking the higher price of transition-metals into consideration, recently, transitionmetal-free synthesis of 2 -substituted benzo[b]furans was developed in the presence of stoichiometric ${ }^{20}$ or catalytic amount ${ }^{21}$ of base (Scheme 1a) and by photochemical ${ }^{22}$ or oxidative ${ }^{23}$ routes. Nevertheless, high catalyst-loading, harsh reaction conditions such as high reaction temperature and indispensable microwave, limited substrates compatibility and low chemselectivity for the desired 2-substituted benzo[ $b]$ furans products still bring some restrictions to their practical applications. Therefore, transition-metal-free catalytic systems with easily accessible and inexpensive catalysts and gentle reaction conditions for
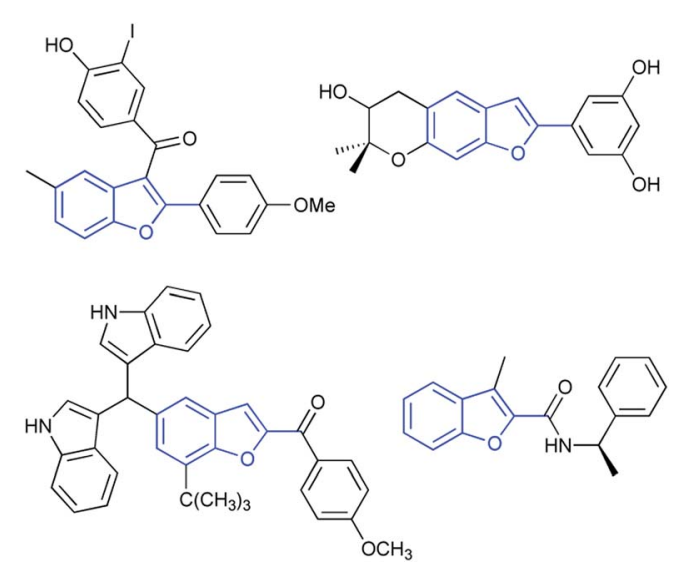

Fig. 1 Pharmaceutically and biologically active molecules bearing 2substituted benzo[b]furans skeletons. 
Previous work:

a

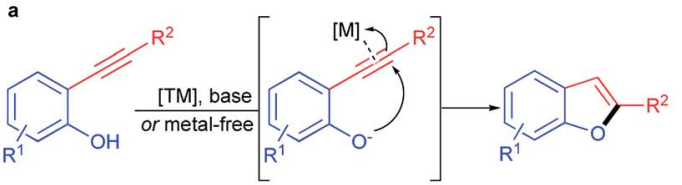

[TM]: Pd, Pt, Au, Ag, Ir, Rh, Cu, Zn, etc.

Metal-free: stoichiometric or high catalyst-loading with hash conditions

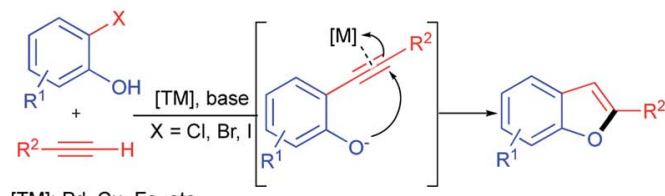

[TM]: Pd, $\mathrm{Cu}, \mathrm{Fe}$, etc

Ligands and high reaction temperature were unavoidable.

This work

c

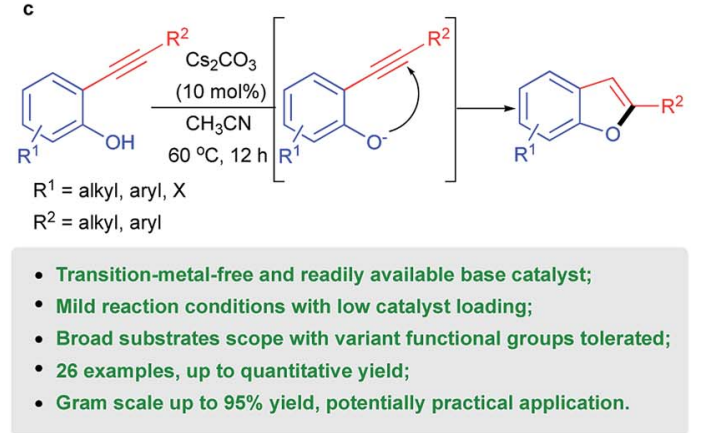

Scheme 1 Previous synthetic methods for 2-substituted benzo[b] furans and the present metal-free catalytic system.

efficient and facile synthesis of 2-substituted benzo[ $b]$ furans are still highly desirable. Herein, we report a facile method for the synthesis of 2 -substituted benzo[ $b]$ furans catalyzed by readily available base at the absence of transition metals (Scheme 1c). In the present work, a broad array of 2-aryl and 2-alkyl substituted benzo[b]furans can be obtained with excellent yields from the efficacious intramolecular cyclization of the corresponding 2-ynylphenols catalyzed by easily accessible $\mathrm{Cs}_{2} \mathrm{CO}_{3}$ at mild reaction conditions. And the semi-gram and gram scale transformations could also be realized with excellent isolated yields which represents this protocol a potentially practical method for the synthesis of 2-substituted benzo[ $b]$ furans derivatives.

\section{Results and discussion}

Our studies commenced with the intramolecular cyclization of 2-(phenylethynyl)phenol 1a as the model reaction and a variety of bases were evaluated in view of their easy accessibility and key role based on previous catalytic systems using acetonitrile as solvent at $60{ }^{\circ} \mathrm{C}$. Firstly, a serious of readily available inorganic bases were examined for the titled reaction. As can be seen from Table 1, commonly used hydroxides of alkalis especially $\mathrm{KOH}$ exhibited good catalytic activity toward the formation of 2a with $89 \%$ isolated yield (Table 1, entries 1 and 2). To our delight, it was found that a quantitative yield of $2 \mathrm{a}$ could be obtained when cesium carbonate was used as the catalyst (Table
Table 1 Optimization of reaction conditions

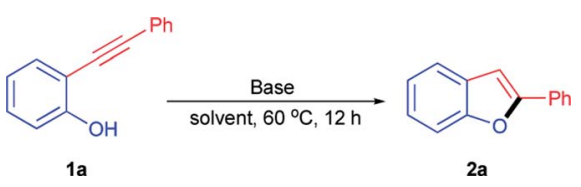

\begin{tabular}{|c|c|c|c|}
\hline Entry $^{a}$ & Base & Solvent & Yield $^{b}(\%)$ \\
\hline 1 & $\mathrm{NaOH}$ & $\mathrm{CH}_{3} \mathrm{CN}$ & 28 \\
\hline 2 & $\mathrm{KOH}$ & $\mathrm{CH}_{3} \mathrm{CN}$ & 89 \\
\hline 3 & $\mathrm{Na}_{2} \mathrm{CO}_{3}$ & $\mathrm{CH}_{3} \mathrm{CN}$ & Trace \\
\hline 4 & $\mathrm{~K}_{2} \mathrm{CO}_{3}$ & $\mathrm{CH}_{3} \mathrm{CN}$ & 21 \\
\hline 5 & $\mathrm{Cs}_{2} \mathrm{CO}_{3}$ & $\mathrm{CH}_{3} \mathrm{CN}$ & $>99$ \\
\hline 6 & $t$-BuOK & $\mathrm{CH}_{3} \mathrm{CN}$ & 21 \\
\hline 7 & NaOMe & $\mathrm{CH}_{3} \mathrm{CN}$ & 7 \\
\hline 8 & NaOEt & $\mathrm{CH}_{3} \mathrm{CN}$ & $\mathrm{ND}^{c}$ \\
\hline 9 & NaOAc & $\mathrm{CH}_{3} \mathrm{CN}$ & ND \\
\hline 10 & $\mathrm{Et}_{3} \mathrm{~N}$ & $\mathrm{CH}_{3} \mathrm{CN}$ & Trace \\
\hline 11 & Pyridine & $\mathrm{CH}_{3} \mathrm{CN}$ & ND \\
\hline 12 & Piperidine & $\mathrm{CH}_{3} \mathrm{CN}$ & 5 \\
\hline $13^{d}$ & DBU & $\mathrm{CH}_{3} \mathrm{CN}$ & 41 \\
\hline 14 & - & $\mathrm{CH}_{3} \mathrm{CN}$ & ND \\
\hline 15 & $\mathrm{Cs}_{2} \mathrm{CO}_{3}$ & Toluene & 18 \\
\hline 16 & $\mathrm{Cs}_{2} \mathrm{CO}_{3}$ & THF & 14 \\
\hline 17 & $\mathrm{Cs}_{2} \mathrm{CO}_{3}$ & 1,4-Dioxane & 31 \\
\hline $18^{e}$ & $\mathrm{Cs}_{2} \mathrm{CO}_{3}$ & DCE & 20 \\
\hline 19 & $\mathrm{Cs}_{2} \mathrm{CO}_{3}$ & EtOAc & 31 \\
\hline 20 & $\mathrm{Cs}_{2} \mathrm{CO}_{3}$ & Acetone & 10 \\
\hline 21 & $\mathrm{Cs}_{2} \mathrm{CO}_{3}$ & $\mathrm{H}_{2} \mathrm{O}$ & 54 \\
\hline 22 & $\mathrm{Cs}_{2} \mathrm{CO}_{3}$ & EtOH & 78 \\
\hline 23 & $\mathrm{KOH}$ & THF & ND \\
\hline 24 & $\mathrm{KOH}$ & Acetone & 9 \\
\hline 25 & $\mathrm{KOH}$ & $\mathrm{H}_{2} \mathrm{O}$ & 23 \\
\hline 26 & $\mathrm{KOH}$ & EtOH & 80 \\
\hline $27^{f}$ & $\mathrm{Cs}_{2} \mathrm{CO}_{3}$ & $\mathrm{CH}_{3} \mathrm{CN}$ & 20 \\
\hline $28^{g}$ & $\mathrm{Cs}_{2} \mathrm{CO}_{3}$ & $\mathrm{CH}_{3} \mathrm{CN}$ & 9 \\
\hline $29^{h}$ & $\mathrm{Cs}_{2} \mathrm{CO}_{3}$ & $\mathrm{CH}_{3} \mathrm{CN}$ & 21 \\
\hline $30^{i}$ & $\mathrm{Cs}_{2} \mathrm{CO}_{3}$ & $\mathrm{CH}_{3} \mathrm{CN}$ & 89 \\
\hline $31^{j}$ & $\mathrm{Cs}_{2} \mathrm{CO}_{3}$ & $\mathrm{CH}_{3} \mathrm{CN}$ & 91 \\
\hline
\end{tabular}

${ }^{a}$ Reaction conditions: 2-(phenylethynyl)phenol $1 \mathrm{a}(0.3 \mathrm{mmol})$, base $(10 \mathrm{~mol} \%)$, solvent $(3 \mathrm{~mL}), 60{ }^{\circ} \mathrm{C}, 12 \mathrm{~h} .{ }^{b}$ Isolated yields. ${ }^{c} \mathrm{ND}$, not detected. ${ }^{d}$ DBU, 1,8-diazabicyclo[5.4.0]undec-7-ene. ${ }^{e}$ DCE, 1,2dichloro ethane. ${ }^{f} 5$ mol\% $\mathrm{Cs}_{2} \mathrm{CO}_{3}$ was used. ${ }^{g} 40{ }^{\circ} \mathrm{C} .{ }^{h} 6 \mathrm{~h}^{i}{ }^{i} 8 \mathrm{~h} .{ }^{j} 10 \mathrm{~h}$.

1, entry 5), although other carbonates of alkalis such as $\mathrm{Na}_{2} \mathrm{CO}_{3}$ and $\mathrm{K}_{2} \mathrm{CO}_{3}$ displayed poor even none efficiency toward the cyclization of $1 \mathbf{a}$ (Table 1, entries 3 and 4). The excellent catalytic activity of $\mathrm{Cs}_{2} \mathrm{CO}_{3}$ could be attributed to its stronger basicity and better solubility in acetonitrile compared with other inorganic bases, ${ }^{24}$ which endowed it with a powerful ability to activate 2 (phenylethynyl)phenol 1a. To the contrary, other commonly used strong bases such as $t$-BuOK, NaOMe and NaOEt exhibited poor even none activity for the transformation of 1a to $2 \mathbf{a}$ (Table 1, entries 6-8). Consequently, it was understandable that weaker base like NaOAc displayed no activity at all (Table 1, entry 9). In addition, several commonly used organic bases were also tested under the identical reaction conditions. As a result, only a low yield was given when the relatively strong base DBU was used as the catalyst (Table 1 , entry 13) while other organic bases tested here were nearly completely negative for the formation of 2a (Table 1, entries 10-12), which could be 
Table 2 Substrates scope $\mathrm{e}^{a, b}$

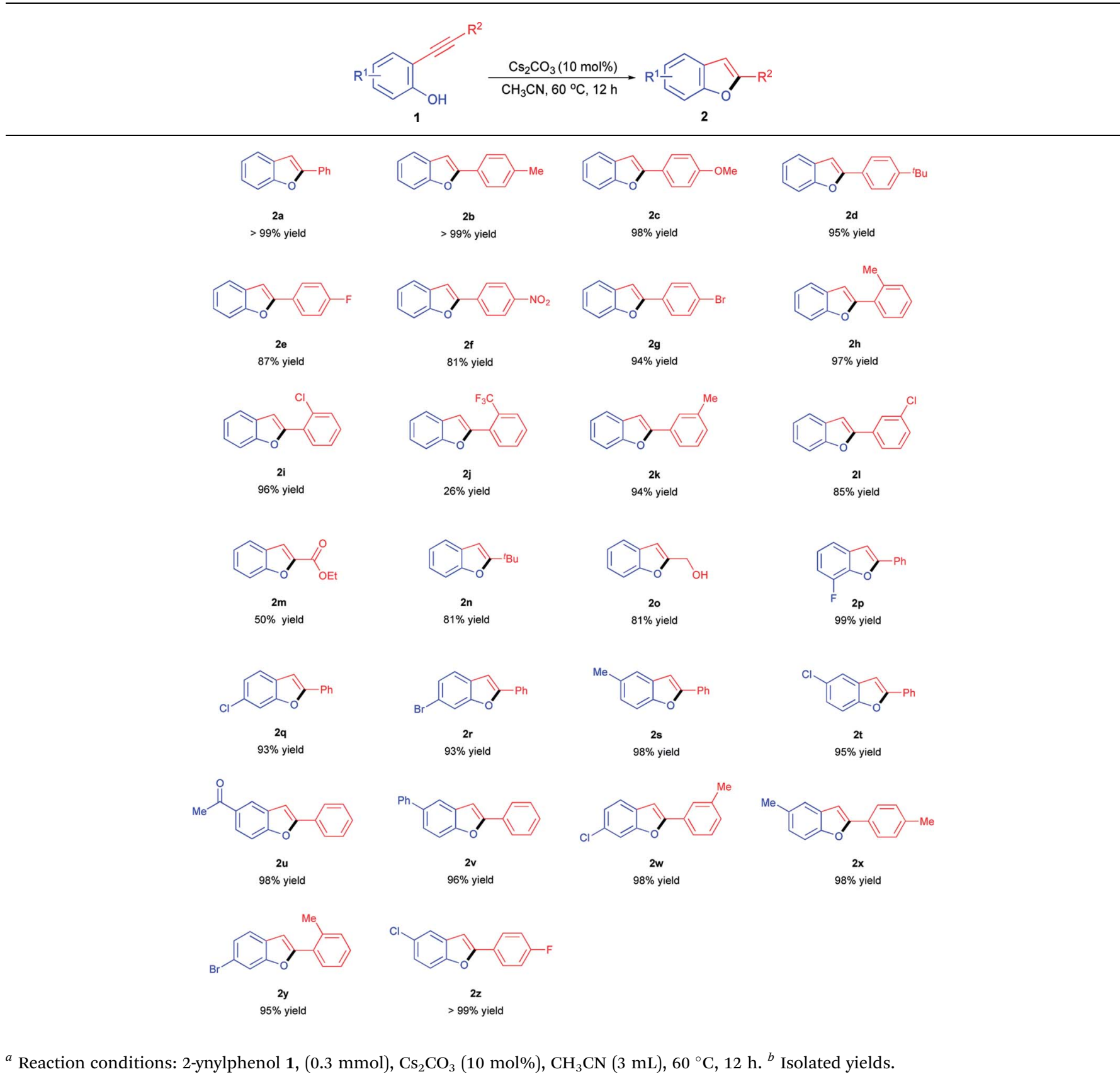

ascribable to their weak basicity for the efficient activation of 1a. It was worth noting that there was no corresponding 2-phenylbenzo[ $b]$ furan 2 a product detected at all in the absence of the base catalyst which could further prove the activation role of $\mathrm{Cs}_{2} \mathrm{CO}_{3}$ to $1 \mathrm{a}$ and thus its catalytic characteristic for this transformation (Table 1 , entry 5 vs. entry 14). Therefore, $\mathrm{Cs}_{2} \mathrm{CO}_{3}$ was chosen as the optimal catalyst and then different solvents were further screened. It was found that the cyclization of 1a to 2a was quite inefficient both in nonpolar solvent such as toluene (Table 1, entry 15) and other medium polar aprotic solvents like THF, 1,4-dioxane, 1,2-dichloroethane, ethyl acetate and acetone (Table 1, entries 16-20), which probably ascribe to the poor solubility of $\mathrm{Cs}_{2} \mathrm{CO}_{3}$ in them. When it comes to the polar protic solvents such as $\mathrm{H}_{2} \mathrm{O}$ and ethanol, moderate yields could be obtained (Table 1, entries 21 and 22) with the increase of the solubility of both substrate and catalyst. Thus, acetonitrile could be proved to be the best solvent for the cyclization of 2-ynylphenol catalyzed by $\mathrm{Cs}_{2} \mathrm{CO}_{3}$. As comparison, it was found that acetonitrile was also the best solvent for $\mathrm{KOH}$, which also exhibited good catalytic activity toward the cyclization of 2ynylphenol, through control experiments (entries 2 vs. 23-26). At the same time, it was observed that either lower catalyst loading or lower reaction temperature was unfavourable for the transformation of 1a to 2a (entry $5 v s$. entries 27 and 28). On the 
other hand, $12 \mathrm{~h}$ was necessary for the complete conversion of 1a to 2 a (entry $5 v s$. entries 29-31) with a satisfactory yield.

With the optimal reaction conditions in hand (Table 1, entry 5), we began to explore the substrates scope of the intramolecular cyclization of different 2-ynylphenols. Inspiringly, a wide array of 2arylynyl and 2-alkylynyl substituted phenols were compatible to the present protocol and a variety of functional groups were tolerated (Table 2). Generally, almost all of the 2-arylynyl phenols bearing either electron-donating or electron-withdrawing substitutes on the ynyl-moiety could react smoothly to afford the corresponding 2-aryl-substituted benzo[b]furans products with good to quantitative yields (Table 2, $\mathbf{2 a - 2 i}, \mathbf{2} \mathbf{k}-\mathbf{2} \mathbf{l}$ ). However, with a $-\mathrm{CF}_{3}$ group on the ynyl-moiety, only $26 \%$ yield was achieved for the related benzo $[b]$ furan product under the optimal conditions which might ascribe to the passivation caused by the $-\mathrm{CF}_{3}$ moiety (Table $2,2 \mathrm{j}$ ). Additionally, moderate to good yields could be obtained for 2-alkyl substituted benzo[ $b]$ furans and either ester group or hydroxyl could tolerate this basic reaction system (Table 2, 2m-2o). On the other hand, substrates bearing either electron-donating groups or electron-withdrawing groups such as halogens, methyl, phenyl and acetyl that located at different positions of the phenol-ring-moiety could also readily be transformed into the desired 2-substituted benzo $[b]$ furans products with good to excellent yields (Table 2, 2p$2 \mathbf{v}$ ). Besides that, it was worth noting that the present protocol was also highly active for 2-ynylphenols bearing substitutes both on the ynyl-moiety and on the phenol-ring-moiety. As a result, several polysubstituted benzo[ $b]$ furans derivatives could be approached with excellent to quantitative yields (Table $2, \mathbf{2 w}-\mathbf{2 z}$ ).

In order to evaluate the practical application of the present metal-free catalytic system, both the semi-gram and gram scale patterns were conducted using several 2-ynylphenols bearing different substitutes. As can be seen from Scheme 2, excellent yields could be obtained for both semi-gram and gram scale patterns under the optimal reaction conditions for the tested 2ynylphenols, which indicated ideal maintenances of the vigorous efficiency of this catalytic system and enabled the present methodology potentially practical application for facile synthesis of 2-substituted benzo[ $b]$ furans derivatives.

A plausible reaction mechanism is proposed as shown in Scheme 3. Firstly, 2-(phenylethynyl)phenol 1a can be activated through a deprotonation by $\mathrm{Cs}_{2} \mathrm{CO}_{3}$ with the formation of the nucleophilic phenolate intermediate $\mathbf{I}$. Then an intramolecular nucleophilic cyclization of phenolate I to acetenyl, which might be activated by cesium ion through a metal- $\pi$ activation, could

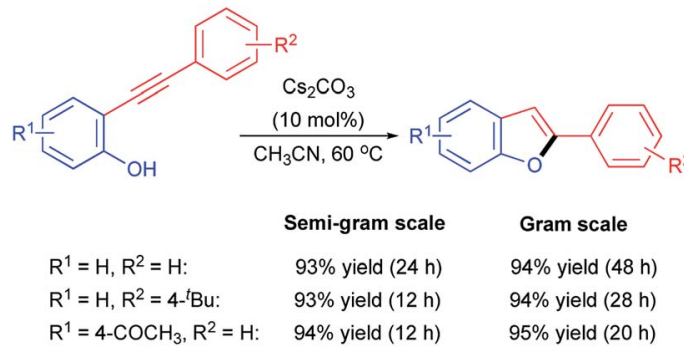

Scheme 2 Semi-gram and gram scale reactions for $\mathrm{Cs}_{2} \mathrm{CO}_{3}$ catalyzed cyclization of 2-ynylphenols toward 2-substituted benzo[b]furans.

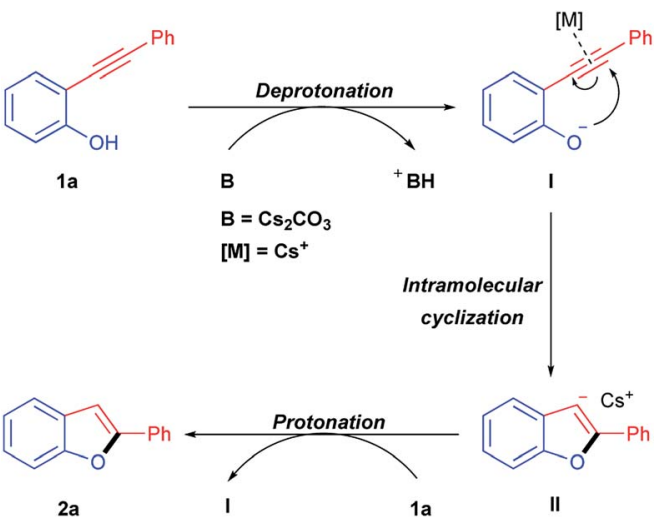

Scheme 3 Plausible reaction mechanism.

afford the benzo[ $[b]$ furan anion intermediate II. And the subsequent protonation of intermediated II by 2-(phenylethynyl) phenol could give the final product 2-phenylbenzo[b]furan 2a accompanied with the generation of phenolate intermediate I for further cyclization to afford benzo $[b]$ furan product.

\section{Conclusions}

In conclusion, we have developed an efficacious protocol for the synthesis of 2-substituted benzo[b]furans through a transitionmetal-free $\mathrm{Cs}_{2} \mathrm{CO}_{3}$ catalyzed intramolecular cyclization of 2ynylphenols under mild reaction conditions. Notably, the wide substrates scope and the typical maintenance of the excellent catalytic efficiency for gram scale enable the present method to be a potentially practical protocol for facile synthesis of 2substituted benzo $[b]$ furan derivatives.

\section{Experimental}

\section{General procedure for $\mathrm{Cs}_{2} \mathrm{CO}_{3}$ catalyzed intramolecular annulation of 2-ynylphenols to 2-substituted benzo[b]furans}

To a sealed tube with a magnetic bar were added 2-ynylphenols $1(0.3 \mathrm{mmol})$ and acetonitrile $(3 \mathrm{~mL})$. After stirring at r.t. for $5 \mathrm{~min}, \mathrm{Cs}_{2} \mathrm{CO}_{3}(10 \mathrm{~mol} \%)$ was added and the resulting mixture was stirred at $60{ }^{\circ} \mathrm{C}$ for 12 hours. After cooling, the obtained mixture was filtered and the residue was washed twice with acetonitrile. Then the filtrate was evaporated under reduced pressure to remove the solvent and the residue was purified by flash column chromatography to obtain the corresponding 2substituted benzo[b]furans 2 .

\section{Conflicts of interest}

There are no conflicts to declare.

\section{Acknowledgements}

We are grateful to the National Natural Science Foundation of China (No. 21502231 and 21572273) and the Fundamental Research Funds for the Central Universities (No. 2015PY004) for 
financial supports. And we also thank Prof. Liang-Nian He from Nankai University for the help on EI-HRMS test.

\section{Notes and references}

1 B. A. Keay, J. M. Hopkins and P. W. Dibble, in Comprehensive Heterocyclic Chemistry III, ed. A. R.Katrizky, Pergamon Press, New York, 1984, vol. 3, p. 571.

2 H. K. Shamsuzzaman, Eur. J. Med. Chem., 2015, 97, 483.

3 R. Naik, D. S. Harmalkar, X.-Z. Xu, K. Jang and K. Lee, Eur. J. Med. Chem., 2015, 90, 379.

4 K. V. Sashidhara, R. K. Modukuri, R. Sonkar, K. B. Rao and G. Bhatia, Eur. J. Med. Chem., 2013, 68, 38.

5 X.-Z. Jiang, W.-L. Liu, W. Zhang, F.-Q. Jiang, Z. Gao, H. Zhuang and L. Fu, Eur. J. Med. Chem., 2011, 46, 3526.

6 Y.-S. Xie, D. Kumar, V. D. V. Bodduri, P. S. Tarani, B.-X. Zhao, J.-Y. Miao, K. Jang and D.-S. Shin, Tetrahedron Lett., 2014, 55, 2796.

7 For Pt catalyzed examples, see: (a) A. Fürstner and P. W. Davies, J. Am. Chem. Soc., 2005, 127, 15024; (b) C. A. Witham, W.-Y. Huang, C. K. Tsung, J. N. Kuhn, G. A. Somorjai and F. D. Toste, Nat. Chem., 2010, 2, 36; (c) Y.-M. Li, J. H. Liu, C. A. Witham, W. Y. Huang, M. A. Marcus, S. C. Fakra, P. Alayoglu, Z.-W. Zhu, C. M. Thompson, A. Arjun, K. Lee, E. Gross, F. D. Toste and G. A. Somorjai, J. Am. Chem. Soc., 2011, 133, 13527.

8 For Pd catalyzed examples, see: (a) Y. Liang, S. Tang, X.-D. Zhang, L.-Q. Mao, Y.-X. Xie and J.-H. Li, Org. Lett., 2006, 8, 3017; (b) W.-Y. Huang, J.-H. Liu, P. Alayoglu, Y.-M. Li, C. A. Witham, C.-K. Tsung, F. D. Toste and G. A. Somorjai, J. Am. Chem. Soc., 2010, 132, 16771; (c) M. Kim, S. Lee, K. Kim, D. Shin, H. Kim and H. Song, Chem. Commun., 2014, 50, 14938; (d) P. Rubio-Marques, M. A. Rivero-Crespo, A. Leyva-Perez and A. Corma, J. Am. Chem. Soc., 2015, 137, 11832.

9 Y. Zhang, Z.-J. Xin, J.-J. Xue and Y. Li, Chin. J. Chem., 2008, 26, 1461.

10 For Au catalyzed examples, see: (a) V. Belting and N. Krause, Org. Lett., 2006, 8, 4489; (b) A. S. K. Hashmi, T. D. Ramamurthi and F. Rominger, Adv. Synth. Catal., 2010, 352, 971; (c) O. S. Morozov, A. V. Lunchev, A. A. Bush, A. A. Tukov, A. F. Asachenko, V. N. Khrustalev, S. S. Zalesskiy, V. P. Ananikov and M. S. Nechaev, Chem.Eur. J., 2014, 20, 6162; (d) L.-B. Kong, R. Ganguly, Y.-X. Li and R. Kinjo, Chem. Sci., 2015, 6, 2893; (e) Z.-H. Xia, O. Khaled, V. Mouriès-Mansuy, C. Ollivier and L. Fensterbank, J. Org. Chem., 2016, 81, 7182; (f) J. Zhao, S. C. Nguyen, R. Ye, B.-H. Ye, H. Weller, G. A. Somorjai, A. P. Alivisatos and F. D. Toste, ACS Cent. Sci., 2017, 3, 482. 11 For Rh catalyzed examples, see: (a) B. M. Trost and A. McClory, Angew. Chem., Int. Ed., 2007, 46, 2074; (b) N. Isono and M. Lautens, Org. Lett., 2009, 11, 1329; (c) A. Boyer, N. Isono, S. Lackner and M. Lautens, Tetrahedron, 2010, 66, 6468; (d) A. Sarbajna, P. Pandey, S. M. W. Rahaman, K. Singh, A. Tyagi, P. H. Dixneuf and J. K. Bera, ChemCatChem, 2017, 9, 1397.
12 X.-W. Li, A. R. Chianese, T. Vogel and R. T. Carbtree, Org. Lett., 2005, 7, 5437.

13 M. Nakamura, L. Ilies, S. Otsubo and E. Nakamura, Angew. Chem., Int. Ed., 2006, 45, 944.

14 For $\mathrm{Cu}$ catalyzed examples, see: (a) K. Hiroya, S. Itoh and T. Sakamoto, Tetrahedron, 2005, 61, 10958; (b) M. Nakamura, L. Ilies, S. Otsubo and E. Nakamura, Org. Lett., 2006, 8, 2803.

15 C. E. Castro, E. J. Gaughan and D. C. Owsley, J. Org. Chem., 1966, 31, 4071.

16 For Pd catalyzed one-pot synthesis of 2-substituted benzo[ $b]$ furans, see: (a) A. Arcadi, F. Marinelli and S. Cacchi, Synthesis, 1986, 9, 749; (b) M. C. Kabalka, L. Wang and R. M. Pagni, Tetrahedron, 2001, 57, 8017; (c) M. A. Berliner, E. M. Cordi, J. R. Dunetz and K. E. Price, Org. Process Res. Dev., 2010, 1, 180; (d) J.-R. Wang and K. Manabe, J. Org. Chem., 2010, 75, 5340; (e) M. Thevenin, S. Thoret, P. Grellier and J. Dubois, Bioorg. Med. Chem., 2013, 21, 4885; $(f)$ R. Zhou, W. Wang, Z.-J. Jiang, K. Wang, X.-L. Zheng, H.-Y. Fu, H. Chen and R.-X. Li, Chem. Commun., 2014, 50, 6023; (g) M. Yamaguchi, T. Akiyama, H. Sasou, H. Katsumata and K. Manabe, J. Org. Chem., 2016, 81, 5450.

17 For $\mathrm{Cu}$ catalyzed one-pot synthesis of 2-substituted benzo[ $b]$ furans, see: $(a)$ C. G. Bates, P. Saejueng, J. M. Murphy and D. Venkataraman, Org. Lett., 2002, 4, 4727; (b) E. A. Jaseer, D. J. C. Prasad and G. Sekar, Tetrahedron, 2010, 66, 2077; (c) R. Cano, M. Yus and D. J. Ramón, Tetrahedron, 2012, 68, 1393.

18 For Fe catalyzed one-pot synthesis of 2-substituted benzo[ $b]$ furans, see: (a) M. Carril, A. Correa and C. Bolm, Angew. Chem., Int. Ed., 2008, 47, 4862; (b) J.-G. Yang, G.-D. Shen and D.-B. Chen, Synth. Commun., 2013, 43, 837.

19 For phenols as the starting material, see: $(a)$ L. M. Geary and P. G. Hultin, Org. Lett., 2009, 11, 5478; (b) S.-H. Wang, P.-H. Li, L. Yu and L. Wang, Org. Lett., 2011, 13, 5968; (c) L. Arias, Y. Vara and F. P. Cossío, J. Org. Chem., 2012, 77, 266; (d) U. Sharma, T. Naveen, A. Maji, S. Manna and D. Maiti, Angew. Chem., Int. Ed., 2013, 52, 12669.

20 (a) J. Hu, L. Liu, X.-C. Wang, Y.-Y. Hu, S.-D. Yang and Y.-M. Liang, Green Sustainable Chem., 2011, 1, 165; (b) K. Damera, B. Ke, K. Wang, C. Dai, L. Wang and B. Wang, RSC Adv., 2012, 2, 9403.

21 For base catalyzed examples, see: (a) I. R. Siddiqui, M. A. Waseem, S. Shamim, Shireen, A. Srivastava and A. Srivastava, Tetrahedron Lett., 2013, 54, 4154; (b) S.-X. Sun, J.-J. Wang, Z.-J. Xu, L.-Y. Cao, Z.-F. Shi and H.-L. Zhang, Tetrahedron, 2014, 70, 3798.

22 S. Protti, M. Fagnoni and A. Albini, J. Org. Chem., 2012, 77, 6473.

23 L. Liu, X.-Y. Ji, J.-Y. Dong, Y.-B. Zhou and S.-F. Yin, Org. Lett., 2016, 18, 3138.

24 F. Lehmann, Synlett, 2004, 13, 2447. 